\title{
ANALISIS KETERAMPILAN BERMAIN ALAT MUSIK ANGKLUNG PADA SISWA SEKOLAH DASAR
}

\author{
Siska Kusumawardani ${ }^{1}$, Nanda Nur Aulia ${ }^{2}$
}

Universitas Muhammadiyah Jakarta, Indonesia

Email: siskakusumawardani89@gmail.com

\begin{tabular}{|c|c|}
\hline Info Artikel & Abstract \\
\hline Sejarah Artikel: & $\begin{array}{l}\text { The purpose of this study was to analyze and describe the skills of playing angklung } \\
\text { musical instruments in elementary school children. }\end{array}$ \\
\hline Diserahkan 4 Juli 2020 & The research method in this research is descriptive research with observation, \\
\hline Direvisi 20 November 2020 & documentation and interview data. The research was conducted at SD Private Syafana \\
\hline Disetujui 21 November 2020 & $\begin{array}{l}\text { Islamic School with the subjects studied were } 10 \text { children who were a combination of low } \\
\text { classes, namely class 1,2,3. Data analysis using descriptive-qualitative analysis. }\end{array}$ \\
\hline $\begin{array}{l}\text { Keywords: } \\
\text { skill, musik instrument, } \\
\text { angklung. }\end{array}$ & $\begin{array}{l}\text { The results showed that the skills to play angklung consisted of 1) preparation consisting of } \\
\text { recruiting children to enter extra angklung musical instruments. 2) Preparation, formulate } \\
\text { learning objectives to play angklung, determine methods in playing angklung skills 3) } \\
\text { implementation. a) the teacher conveys the learning objectives and provides material about } \\
\text { the angklung musical instrument b) the teacher demonstrates the angklung, how to hold, }\end{array}$ \\
\hline & $\begin{array}{l}\text { how to play the resulting tone. c). given training using angklung and 4) evaluation by } \\
\text { holding an art performance playing angklung which is held in schools through audience } \\
\text { appreciation. }\end{array}$ \\
\hline
\end{tabular}

\begin{abstract}
Abstrak
Tujuan penelitian ini adalah untuk menganalisis dan mendeskripsikan keterampilan bermain alat musik angklung pada anak SD.

Metode penelitian pada penelitian ini adalah penelitian deskriptif dengan pengumpulan data yaitu observasi, dokumentasi dan wawancara. Penelitian dilakukan di SD swasta Syafana Islamic School dengan subyek yang diteliti 10 anak yang merupakan gabungan dari kelas rendah yaitu kelas 1,2,3. Analisis data menggunakan analisis deskriptif-kualitatif. Hasil penelitian menunjukkan keterampilan bermain alat musik angklung terdiri dari 1) pra persiapan yang terdiri dari pengrekrutan anak untuk masuk ekstra alat musik angklung. 2) persiapan meliputi merumuskan tujuan pembelajaran bermain angklung, penentuan metode pengajaran dalam keterampilan bermain angklung 3) pelaksanaan. a) guru menyampaikan tujuan pembelajaran dan memberikan materi tentang alat musik angklung b) guru mendemontrasikan angklung, cara memegang, cara memainkan nada yang dihasilkan. c).diberikan pelatihan menggunakan angklung dan 4) evaluasi yaitu dengan mengadakan pentas seni bermain angklung yang diadakan di sekolah melalui apresiasi penonton.
\end{abstract}

(C) 2020 Universitas Muria Kudus 
Siska Kusumawardani, Nanda Nur Aulia

ANALISIS KETERAMPILAN BERMAIN ALAT MUSIK ANGKLUNG PADA SISWA ...

REFLEKSI EDUKATIKA : Jurnal Ilmiah Kependidikan, Volume 11, Nomor 1, Desember 2020, hlm. 116-120

\section{PENDAHULUAN}

Pendidikan merupakan salah satu investasi masa depan yang harus disertai dengan melakukan peningkatan, pengembangan dan inovasi pembelajaran. Sudjana (2009) menyatakan bahwa Indikator hasil belajar menurut Bloom dengan taksonominya dibagi menjadi tiga ranah yaitu ranah kognitif, afektif dan psikomotor. Salah satu contoh pengembangan psikomotorik yaitu terlihat dalam bentuk keterampilan dan kemampuan bertindak individu, seperti dengan adanya kegiatan ekstrakulikuler pembelajaran/pelatihan angklung di sekolah. Ekstrakulikuler Angklung merupakan ekstrakulier yang kental dengan budaya yang sudah mendunia.

Angklung merupakan alat musik tradisional Indonesia yang terbuat dari bambu yang dibunyikan dengan cara diguncang (akibat benturan badan pipa bambu) sehingga menghasilkan suara yang hidup dengan komposisi 2, 3 sampai 4 nada pada tiap ukuran, baik ukuran kecil dan besar, pada susunan 2, 3 sampai 4 nada merupakan susunan tabung pada alat musik angklung (Nurhani, 2008). Angklung telah ditetapkan sebagai "Representative List of The Intangible Cultural Heritage of Humanity" oleh UNESCO pada tanggal 18 November 2010 di Nairobi, Kenya (Pradoko, 2013).

Keterampilan bermain musik angklung ini tidak sedikit orang yang melirik untuk mengembangkannya. Penelitian yang dilakukan oleh Erneza (2015) mengadaptasikan permainan alat musik angklung secara manual menjadi permainan musik digital dengan teknologi layar sentuh. Hal ini juga sejalan dengan penelitian yang dilakukan oleh Danal, et al (2017) pembuatan aplikasi simulasi permainan angklung berbasis android dengan hasil penelitian $80 \%$ aplikasi telah memenuhi syarat untuk dianggap baik.

Berdasarkan observasi pada bulan November 2017, terdapat dua faktor yang mempengaruhi pembelajaran dan pelatihan angklung di Sekolah Dasar Syafana Islamic School, yaitu faktor pendukung dan faktor penghambat. Faktor pendukung yang mempengaruhi pelatihan angklung diantaranya adalah media, sarana dan prasarana pembelajaran angklung yang memadai. Berbagai event yang diselenggarakan di Sekolah Dasar Syafana Islamic School seringkali melibatkan kelompok angklung baik diawal, akhir maupun inti acara tersebut. Hal tersebut sebagai faktor pendukung, dimana permainan angklung diperlukan slam berbagai event kegiatan yang diselenggarakan.

Sedangkan faktor penghambat yang ditemui adalah durasi waktu pelatihan bermain angklung. Jarak waktu antara satu event dan event lainnya tidaklah panjang, berkisar antara empat sampai enam belas minggu bahkan dua minggu sekali. Namun, untuk pertemuan pelatihan bermain angklung hanya dilakukan selama dua jam setiap minggunya. Selain itu, materi lagu yang harus berganti di setiap event dan komposisi siswa (pemain) yang tidak menentu inilah yang menjadi faktor penghambat pembelajaran dan pelatihan bermain angklung di Sekolah Dasar Swasta Syafana Islamic School.

Berdasarkan kondisi tersebut, maka perlu adanya metode khusus pembelajaran dan pelatihan yang tepat agar tujuan dari pembelajaran dan pelatihan dapat tercapai sebagaimana mestinya. Selain itu, pembelajaran keterampilan bermain angklung ini diharapkan dapat melestarikan budaya Indonesia. Hal ini sejalan dengan pendapat Putri (2012) dalam penelitiannya bahwa permainan alat musik angklung merupakan alat musik tradisional yang perlu digalakkan agar mendapat tempat di hati generasi muda sehingga dapat mengenal dan melestarikan alat musik angklung.

Berbagai macam cara digunakan dalam meningkatkan kualitas keterampilan bermain alat musik angklung yaitu dengan metode pengajaran yang tepat yaitu melalui pembuatan aplikasi berbasis digital. Keterampilan bermain alat musik angklung merupakan salah satu keterampilan yang tidak mudah didapat tanpa adanya pelatihan. Secara teori keterampilan merupakan usaha menggunakan nalar, ide dan kreativitas saat melakukan, mengubah atau mendekatkan sesuatu sehingga menghasilkan nilai dari hasil pekerjaan. Seseorang akan terampil melakukan sesuatu, baik fisik maupun psikis, jika ia terlatih dan terbiasa melakukan aktivitas tertentu maka seseorang tersebut akan mahir dalam pekerjaan tersebut.

Keterampilan bermain angklung memerlukan pelatihan khusus dan membutuhkan waktu yang tidak singkat. Hal tersebut dikarenakan angklung memiliki beberapa jenis, sehingga pemain harus memahaminya. Azhari (2015) menyatakan pada umumnya jenis-jenis angklung yang ada di Indonesia adalah angklung pentatonis (angklung tradisional) dan angklung diantonis (angklung daeng). 
Siska Kusumawardani, Nanda Nur Aulia

ANALISIS KETERAMPILAN BERMAIN ALAT MUSIK ANGKLUNG PADA SISWA ...

REFLEKSI EDUKATIKA : Jurnal Ilmiah Kependidikan, Volume 11, Nomor 1, Desember 2020, hlm. 116-120

Berdasarkan latar belakang di atas tujuan penelitian ini adalah untuk menganalisis dan mendeskripsikan keterampilan bermain alat musik angklung di sekolah dasar.

\section{METODE PENELITIAN}

Metode yang digunakan dalam penelitian ini adalah deskriptif kualitatif karena dalam penelitian ini akan dibahas fenomena kejadian yang terjadi di lapangan dengan mendeskripsikan, memaparkan, menggambarkan dan menganalisis proses keterampilan bermain alat musik angklung.

Penelitian ini dilaksanakan di SD swasta Syafana Islamic School yang terletak di J1. Curug Sangereng No. 1, Paradiso, Gading Serpong, Curug Sangereng, Kelapa Dua, Tangerang, Banten 15332. Penelitian ini dilakukan kepada 10 anak SD yang terdiri dari siswa kelas 1,2 , dan 3. Penelitian dilakukan selama 4 bulan dari mulai januari 2018 hingga April 2018.

Teknik pengumpulan data pada penelitian ini terdiri dari wawacara, observasi dan dokumentasi, teknik keabsahan data dan analisis data. Analisis data dalam penelitian ini mencangkup 3 tahap yaitu reduksi data, penyajian data, dan penarikan kesimpulan. Datadata yang dihasilkan dikumpulkan kemudian direduksiberdasarkan jenis data dan kelayakan. Selanjutnya ditarik kesimpulan untuk memverifikasi keabsahan. Jika terdapat data yang kurang atau tertinggal pada saat pengumpulan data, analisis data maka dapat diulang kembali.

\section{HASIL DAN PEMBAHASAN}

Proses penelitian yang dilaksanakan di SD Syfana Islamic School ini berada di Tangerang, Banten. Permainan alat musik angklung ini merupakan salah satu ekstrakurikuler yang cukup diminati di SD Syfana Islamic School dikarenakan fasilitas juga sudah memadai. Namun waktu pembelajaran yang relative singkat sehingga membuat anak jadi terlihat tertekan. Penelitian ini dilaksanakan setiap hari jumat pada waktu ekstrakurikuler dijadwalkan selama 1 jam dimulai pukul 10.00 pagi. Peserta yang mengikuti kegiatan ekstrakulikuer angklung pada hari jumat terlihat banyak sekitar lebih dari 20 anak. Namun menjelang diadakannya pentas seni, dilakukan pemilihan siswa sebanyak 10 orang anak yang akan ditampilkan di kegiatan pentas seni. Untuk menghindari kecemburuan sosial antar siswa, maka setiap anak akan diberikan kesempatan untuk tetap bisa tampil di pentas seni selanjutnya dikarenakan pentas seni akan dilaksanakan selama 3 bulan sekali tutur Aulia pelatih angklung.

Tahap pra persiapan yang dilakukan oleh pelatih yaitu seleksi pemilihan pemain angklung yang dilakukan untuk mematangkan keterampilan bermain angklung agar pada saat pentas seni siswa merasa percaya diri dalam memainkan alat musik angklung. Audisi dilakukan secara terbuka dengan cara menginformasikan kepada seluruh siswa jika akan ada pemilihan 10 orang terbaik pertama untuk ditampilkan pada pentas seni bulan depan sisanya akan tampil di pentas seni selanjutnya.

Setelah mendapat 10 anak yang akan melakukan pentas seni strategi yang dilakukan pelatih yaitu melakukan tahap persiapan yaitu dengan memberikan materi pembalajaran tentang bermain angklung. Pelatih membuat rancangan pembelajaran dengan menggunakan metode yang cocok agar keterampilan bermain anak dalam bermain angklung tidak monoton.

Metode pengajaran yang dinilai cocok dalam memberikan pelatihan bermain musik angklung ini adalah bermain sambil belajar. Menurut Bruner (dalam Mulyadi, 1997) bahwa setiap anak memiliki insting untuk bermain. Ardianti, dkk (2017) berpendapat bahwa sifat alamiah yang dimiliki oleh anak usia sekolah dasar salah satunya adalah bermain. Bermain adalah hal yang serius karena bermain adalah suatu cara bagi anak untuk meniru orang dewasa dan berusaha menguasainya hingga matang. Metode ini sudah berkembang pada semua jenjang pendidikan baik tingkat anak-anak hingga dewasa. Para pelatih tidak hanya menyuruh anak-anaknya duduk diam namun mendorong anak untuk aktif, komunikasi secara langsung sehingga anak lebih berkembang dan di pacu untuk berfikir. Menurut Wicaksono (2009) berdasarkan prinsip musik yang fleksibel, pembelajaran musik tidak dapat menggunakan metode yang berpusat pada guru dikarena akan mengurangi efektivitas dalam pencapaian tujuan pembelajaran. Dewi, et al (2019) menyampaikan bahwa metode pembelajaran yang berpusat pada siswa sebagai metode pembelajaran yang diharapkan diterapkan untuk dapat meningkatkan keterampilan siswa. Apabila siswa aktif berlatih memainkan angklung, maka akan menjadikan siswa lebih terampil memainkannya. 
Siska Kusumawardani, Nanda Nur Aulia

ANALISIS KETERAMPILAN BERMAIN ALAT MUSIK ANGKLUNG PADA SISWA ...

REFLEKSI EDUKATIKA : Jurnal Ilmiah Kependidikan, Volume 11, Nomor 1, Desember 2020, hlm. 116-120

Materi atau bahan ajar bermain angklung termasuk bagian penting dalam pelatihan bermain angklung. Materi pelatihan bermain angklung disajikan dengan menggunakan not berwarna-warni. Hal ini dimaksudkan bahwa dengan menggunakan not warna-warni maka siswa akan tertarik dan dianggap sebagai media bermain angklung.

Not ini juga disajikan dalam bentuk lingkaran dan persegi. Not angka berwarna digunakan untuk menarik perhatian anak dalam memainkan alat musik angklung. Selain itu juga memudahkan anak untuk memainkan lagu yang dimainkan dengan angklung. Misalnya dalam lagu ibu guruku, not berwarna yang ada dalam lagu tersebut terdapat delapan not angka yaitu do, re, mi, fa, sol, la, si , dan do, warna yang dibutuhkan adalah warna biru sebagai nada do, warna merahsebagai nada re, warna kuning sebagai nada mi, warna hijau sebagai nada fa, warna coklat sebagai nada sol, warna putih sebagai nada la, warna hijau sebagai nada si, dan warna pink sebagai warna do tinggi. Not warna ini yang akan diperhatikan oleh anak dalam memainkan alat musik angklung. Masing-masing anak sudah memilih warna sesuai dengan mot lagu yang akan dimainkan. Metode ini telah dilakukan oleh Putri (2012) dalam penelitiannya dan mendapatkan hasil cukup baik dengan $70 \%$ belajar dan $30 \%$ bermain. Ardianti (2015) menambahkan bahwa pengemasan bahan ajar yang menarik akan mengurangi tingkat jenuh dan kebosanan pada diri siswa

Tahap selanjutnya yaitu pelaksanaan kegiatan ekstrakurikuler pelatihan memainkan angklung. Tahap pertama yaitu guru menyampaikan tujuan pembelajaran dan memberikan materi tentang alat musik angklung. Selanjutnya pada tahap kedua guru mendemontrasikan angklung, cara memegang, cara memainkan nada yang dihasilkan. Dengan menggunakan not warna-warna. Penggunaan sumber belajar dan adanya contoh (pemodelan) menjadikan anak akan lebih memahami bagaimana alat musik angklung dimainkan. Karena pembelajaran yang baik menurut Nasution (2016) merupakan proses interaksi anak dengan pelatih dan sumber belajar pada suatu lingkungan belajar. Hal senada juga disampaikan oleh Khakim, et al (2015) bahwa proses pembelajaran yang baik didalamnya terjadi interaksi siswa dengan guru, siswa dengan siswa dan siswa dengan sumber belajar serta lingkungan belajar siswa. Pembelajaran merupakan bantuan yang diberikan pendidik agar dapat terjadi proses perolehan ilmu dan pengetahuan, penguasaan kemahiran dan budi pekerti, serta pembentukan sikap dan kepercayaan pada peserta didik.

Tahap ketiga adalah pelatihan memainkan angklung. Proses latihan memainkan alat musik Angklung dilakukan secara berulang-ulang sehingga diharapkan dapat menanamkan dan memelihara kebiasan-kebiasan tertentu sehingga siswa dapat memiliki ketangkasan atau keterampilan dalam memainkan alat musik angklung dari apa yang telah mereka lakukan proses latihannya.

Tahap terakhir yaitu evaluasi. Evaluasi dilakukan pada saat gladi resik hingga pentas seni melalui apresisi penonton yang antusias dalam menyaksikan permainan angklung. Antusisme penonton yang cukup meriah membuat pemelajaran bermain angklung ini dapat dikatakan berhasil. Pentas seni yang dilakukan menunjukkan hasil belajar alat musik angklung dengan kreativitas. Kreativitas dalam mempelajari alat musik diperlukan untuk mendapatkan pengusaan dan pemahaman yang optimal dalam bidang musik. Bidang musik merupakan bidang yang memiliki banyak dimensi kreatif yang dapat membantu perkembangan optimal pada anak seperti persepsi, visual, auditori, memori, konsentrasi, dan logika (Wicaksono, 2009).

\section{SIMPULAN}

Berdasarkan hasil penelitian di atas peneliti dapat menyimpulkan bahwa analisis keterampilan bermain angklung pada siswa SD di syafana islamic school berjalan dengan beberpa tahap yaitu 1.) pra persiapan yang terdiri dari pengrekrutan anak untuk masuk ekstra alat musik angklung. 2.) persiapan, a) merumuskan tujuan pembelajaran bermain angklung, penentuan metode pengajaran dalam keterampilan bermain angklung 3.) pelaksanaan. a) guru menyampaikan tujuan pembelajaran dan memberikan materi tentang alat musik angklung b) guru mendemontrasikan angklung, cara memegang, cara memainkan nada yang dihasilkan. c) diberikan pelatihan menggunakan angklung. dan 4.) evaluasi yaitu dengan mengadakan pentas seni bermain angklung yang diadakan di sekolah melalui apresiasi penonton. 
Siska Kusumawardani, Nanda Nur Aulia

ANALISIS KETERAMPILAN BERMAIN ALAT MUSIK ANGKLUNG PADA SISWA ...

REFLEKSI EDUKATIKA : Jurnal Ilmiah Kependidikan, Volume 11, Nomor 1, Desember 2020, hlm. 116-120

\section{DAFTAR PUSTAKA}

Ardianti, Sekar Dwi. 2015. Pengaruh Modul Tematik Inquiry-Discovery Terhadap Hasil Belajar Siswa Materi Metabolisme Pembentuk Bionergi. REFLEKSI EDUKATIKA : Jurnal Ilmiah Kependidikan, 5 (2).

Azhari, A. 2015. Jurus Kilat Jago Main Angklung. Bekasi: Laskar Aksara.

Danal, et al. 2017). Aplikasi Simulasi Dan Main Angklung (Saung) Berbasis Android. Jurnal teknologi dan system computer. 5 (1): $38-42$.

Dewi, S.A.P.P.C., Fakhriyah, Fina., dan Purbasari, Imaniar. 2019. Peningkatan Sikap Ilmiah Siswa melalui Guided Inquiry Berbantuan Media Papan Putar Pada Tema Pahlawanku Kelas IV. Jurnal Prakarsa Paedagogia, 2 (2): 198-203.

Khakim, Utaminingsih, Sri., dan Fakhriyah, Fina. 2015. Penerapan Model Contextual Teaching And Learning Melalui Pemanfaatan Lingkungan Sekitar Untuk Meningkatkan Hasil Belajar IPA Kelas V SD 1 Peganjaran Kudus. REFLEKSI EDUKATIKA : Jurnal Ilmiah Kependidikan, 5 (1).

Mulyadi, Seto. 1997. Bermain Itu Penting. Jakarta: PT Elex Media Komputindo.
Nurhani, H. 2008. Intrumen Musik Lengkap. Surakarta: PT. Widya Duta Grafika.

Nasution RA. 2016. Pembelajaran Seni Musik bagi Pengembangan Kognitif Anak Usia Dini. Raudhah, 4 ( 1): 11-21

Pradoko, A. S. 2013. Fenomena Kesenian Angklung Sebagai Bentuk Pertemuan Nilai-nilai Budaya Timur Menuju Barat : Lokal Menuju Global. Prosiding 5 th International Conference on Indonesian Studies : "Ethnicity and GLOBALIZATION", 32-41.

Pratiwi, Ika Ari., Ardianti, Sekar Dwi., dan Kanzunnudin, Moh. 2017. Peningkatan Kemampuan Kerjasama Melalui Model Project Based Learning (PjBL) Berbantu Metode Edutainment Pada Mata Pelajaran Ilmu Pengetahuan Sosial. Refleksi Edukatika: Jurnal Ilmiah Kependidikan, 8 (2): 177-182.

Putri, D.R.K.2012. Pembelajaran Angklung Menggunakan Metode Belajar Sambil Bermain. Harmonia, 12(2): 116-124.

Sudjana, Nana . 2009. Penilaian Hasil Proses Belajar Mengajar. Bandung : PT. Remaja Rosdakarya.

Wicaksono HY. 2009. Kreativitas dalam Pembelajaran Musik. Cakrawala pendidikan. 1 (1): 1-12. 